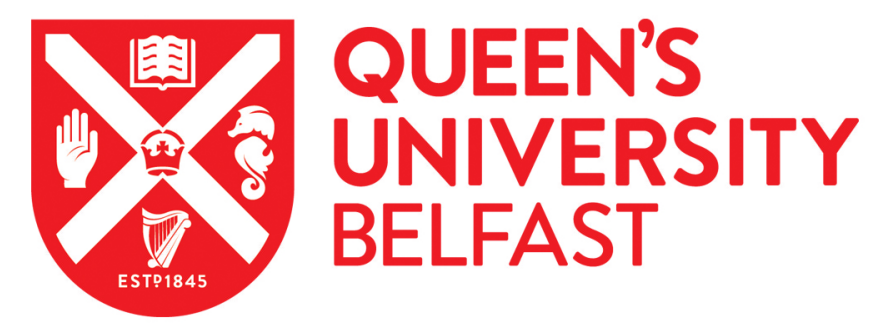

\title{
Ethical issues in palliative care for nursing homes: development and testing of a survey instrument
}

Preshaw, D. H. L., Mclaughlin, D., \& Brazil, K. (2017). Ethical issues in palliative care for nursing homes: development and testing of a survey instrument. Journal of Clinical Nursing. https://doi.org/10.1111/jocn.14118

Published in:

Journal of Clinical Nursing

Document Version:

Peer reviewed version

Queen's University Belfast - Research Portal:

Link to publication record in Queen's University Belfast Research Portal

Publisher rights

(C) 2017 John Wiley \& Son Ltd.

This work is made available online in accordance with the publisher's policies. Please refer to any applicable terms of use of the publisher.

\section{General rights}

Copyright for the publications made accessible via the Queen's University Belfast Research Portal is retained by the author(s) and / or other copyright owners and it is a condition of accessing these publications that users recognise and abide by the legal requirements associated with these rights.

Take down policy

The Research Portal is Queen's institutional repository that provides access to Queen's research output. Every effort has been made to ensure that content in the Research Portal does not infringe any person's rights, or applicable UK laws. If you discover content in the Research Portal that you believe breaches copyright or violates any law, please contact openaccess@qub.ac.uk. 
Ethical issues during palliative care in nursing homes

ETHICAL ISSUES IN PALLIATIVE CARE FOR NURSING HOMES: DEVELOPMENT AND TESTING OF A SURVEY INSTRUMENT

DEBORAH HL PRESHAW (CORRESPONDING AUTHOR) PHD RESEARCH ASSOCIATE

INSTITUTE OF NURSING AND HEALTH RESEARCH, ULSTER UNIVERSITY, SHORE ROAD, NEWTOWNABBEY, BT37 OQB

EMAIL: D.PRESHAW@ULSTER.AC.UK ＴELEPHONE: (028) 90366498

TWITTER: @DEBORAHPRESHAW

DORRY MCLAUGHLIN PHD

LECTURER IN PALLIATIVE CARE AND CHRONIC ILLNESS

(SCHOOL OF NURSING AND MIDWIFERY), QUEEN'S UNIVERSITY, BELFAST, MEDICAL BIOLOGY CENTRE, 97 LISBURN ROAD, BELFAST, BT9 7BL D.MCLAUGHLIN@QUB.AC.UK

KEVIN BRAZIL PHD

PROFESSOR IN PALLIATIVE CARE

(SCHOOL OF NURSING AND MIDWIFERY), QUEEN'S UNIVERSITY, BELFAST, MEDICAL BIOLOGY CENTRE, 97 LISBURN ROAD, BELFAST, BT9 7BL K.BRAZIL@QUB.AC.UK

\section{ACKNOWLEDGEMENTS}

THIS RESEARCH WAS FUNDED BY QUEEN'S UNIVERSITY BELFAST (PHD SCHOLARSHIP). WE THANK DR O. PERRA FOR HIS STATISTICAL GUIDANCE DURING THE ANALYSIS OF THIS RESEARCH. WE ALSO OFFER OUR THANKS TO THE PARTICIPANTS WHO COMPLETED THE SURVEY FOR THEIR TIME AND INSIGHTS. 
Ethical issues during palliative care in nursing homes

\section{ABSTRACT}

Aim. To develop and psychometrically assess a survey instrument identifying ethical issues during palliative care provision in nursing homes.

Background. Registered nurses (RNs) and healthcare assistants (HCAs) have reported ethical issues in everyday palliative care provision. Identifying these issues provides evidence to inform practice development to support healthcare workers.

Design. Cross-sectional survey of RNs and HCAs in nursing homes in one region of the United Kingdom (UK).

Method. A survey instrument, "Ethical issues in Palliative Care for Nursing homes," (EPiCNH) was developed through the findings of qualitative interviews with RNs and HCAs in nursing homes and a literature review. It was reviewed by an expert panel and piloted prior to implementation in a survey in 2015 with a convenience sample of 596 RNs and HCAs. Descriptive and exploratory factor analysis were used to assess the underlying structure of the Frequency and Distress Scales within the instrument.

Results. Analysis of 201 responses (response rate $=33.7 \%$ ) revealed four factors for the Frequency Scale and five factors for the Distress Scale that comprise the EPiCNH. Factors common to both Scales included "Processes of care," "Resident autonomy", and "Burdensome treatment". Additionally, the Frequency Scale included "Competency," and the Distress Scale included "Quality of care," and "Communication." 
Ethical issues during palliative care in nursing homes

Conclusion. The EPiCNH instrument has added to the palliative care knowledge base by considering the ethical issues experienced specifically by RNs and HCAs within the nursing home. This research offers preliminary evidence of the psychometric properties of the EPiCNH survey instrument.

Relevance to practice: The two largest factors highlight the need to address the organisational aspects of caring, and provide training in negotiating conflicting ethical principles.

Keywords: ethical issues, palliative care, nursing homes, instrument development, survey

\section{SUMMARY BOX}

What does this paper contribute to the wider global clinical community?

- This paper reports the psychometric properties of the 26 item EPiCNH survey which examines both Frequency and Level of Distress of ethical issues experienced by healthcare workers in nursing homes

- Organisational issues and issues of conflicting ethical principles primarily need to be addressed, most likely through preventive ethics strategies including improved training in communication strategies.

- Increased training on ethical issues can be tailored to the needs of nursing homes to help manage negative consequences of ethical issues including burnout and high turnover rates. 
Ethical issues during palliative care in nursing homes

\section{INTRODUCTION}

Globally the population of older adults is increasing more rapidly than the total populations in almost every region. Europe is currently the area with the highest proportions of older adults(United Nations 2001). The United Kingdom (UK) population is set to increase by $15 \%$ between 2012 and 2037 , and in the same time frame, the number of people aged 80 and over will more than double (Office for National Statistics 2014). Within the subset of the population aged 65 and over, $40 \%$ have a limiting longstanding illness, and this increases to $69 \%$ in the population aged 85 and over (Age UK 2017).

A significant portion of older people die in long term care settings across Europe, many of whom have complex trajectories of dying, which raises challenges for healthcare practitioners to manage their physical, psychological, social, and spiritual needs through palliative care provision (Froggatt \& Reitinger 2013). However, the average length of nursing home stays has reduced significantly in the UK, therefore, the majority of residents would benefit from palliative care (Guidelines and Audit Implementation Network 2013).

A survey by the Royal College of Nursing (2010) indicated that almost half of nursing homes in the UK reported a nursing staff shortage. This survey also found that there was inadequate equipment available to meet nursing and care needs, and that the mismatch between need and supply was having a detrimental impact on care.

With the pressure on nursing homes increasing, it is likely that the frequency of ethical issues experienced by healthcare workers in the provision of care will also increase. For the purposes of this research, an ethical issue has been 
Ethical issues during palliative care in nursing homes

defined as a "right or wrong" decision to be made that has a moral outcome. At one end of the scale you can be morally comfortable where you have identified an ethical issue and are satisfied with the outcome. The other end of the scale is moral distress, where you witness an ethical issue, but are unsatisfied with the outcome yet are unable to do anything about it due to some external barrier (Preshaw et al, 2016b). Ethical issues in palliative care often arise from concerns about how much, and the appropriate type of care for someone with a limiting, longstanding illness, and there is often conflict between healthcare professionals, patients, and family members about what constitutes appropriate care (Fromme \& Smith 2016). The ethical issues arising from palliative care can be particularly difficult to navigate given the emotional and psychological burden of caring for someone who has a limited life expectancy. One study found healthcare professionals who worked closely with the patients to experience more ethical issues than other staff members (Lillemoen \& Pedersen 2013). In UK nursing homes, registered nurses and healthcare assistants are those who work most closely with the patient and, therefore, are more likely to experience these ethical issues. While an ethical issue can provide an opportunity for learning and change, they can also be associated with detrimental outcomes including moral distress, burnout, and high staff turnover rates (Preshaw et al, $2016 b)$. An increased awareness of this problem may lead to evidence that would help inform practice development to help support healthcare workers in nursing homes.

\section{BACKGROUND}

Previous research has provided limited evidence regarding the nature of ethical issues in nursing homes. A recent review of the international literature by 
Ethical issues during palliative care in nursing homes

Preshaw et al (Preshaw et al. 2015) revealed that the most salient ethical issues within the nursing home included clashing ethical principles, issues related to communication, lack of resources, and quality of care provision. The research to date has been largely qualitative in design and focused on doctors, patients, and other nursing home staff, with few focused specifically on nurses or healthcare assistants, making the findings hard to apply specifically to these groups. The increased likelihood of nurses and healthcare assistants to experience ethical issues, given their proximity to the patient within palliative care, identifies the need for the development of an instrument that recognizes the unique practise characteristics of the nursing home. Based on a review of the literature there is no survey instrument that recognizes the experience of the healthcare workers who provides palliative care in nursing homes. Due to the limited evidence available, a survey instrument has been developed which addresses this gap in the evidence base.

\section{METHODS}

\section{Aim}

The purpose of this study was to develop the "Ethical issues in Palliative care for Nursing Homes" (EPiCNH) survey instrument which measures the frequency of, and level of distress associated with, ethical issues experienced in the provision of palliative care for registered nurses (RNs) and healthcare assistants (HCAs) providing care in nursing homes. In both research and clinical practice, many different definitions of palliative care have been utilised (Pastrana, 2008). This research used the definition by the National Council for Palliative Care (2012), which defines palliative care as "the active holistic care of patients with advanced progressive illness. Management of pain and other

\section{VERSION 4}


Ethical issues during palliative care in nursing homes

symptoms and provision of psychological, social and spiritual support is paramount." The core constituents for palliative care include respect for autonomy, interpersonal relationships between professionals and nonprofessionals, quality of life, communication, education of the public, representation from a multi-disciplinary team, and grief and bereavement.

\section{Design and Methods}

A mixed methodology with an exploratory, sequential, design was adhered to across the overall research study in which this survey development piece was situated. The development of the EPiCNH survey instrument comprised of two stages following the taxonomy of Creswell and Plano-Clark (Creswell \& Plano Clark 2011). The initial instrument development included the generation of items from the literature and a previous qualitative study that examined ethical issues in nursing homes (Preshaw et al, 2016b), followed by an expert panel review of the instrument and pilot testing with RNs and HCAs. The second phase consisted of a cross-sectional survey of RNs and HCAs.

Stage one: instrument development

Item generation

The first stage of item generation was the completion of a literature review. The goal of this review was to identify any previous instruments which have been used to capture ethical or moral issues of nursing staff. Searches were conducted through database searches (CINAHL and Medline), hand searching journals relevant to the topic, a title search on Google Scholar, and exploration of an "ethics tools database" found in the grey literature. The articles retrieved in the literature review by Preshaw et al (2016a) were also checked. Instruments were retrieved from the paper or else the author was contacted requesting the 
Ethical issues during palliative care in nursing homes

instruments. In total 14 instruments were retrieved. All questionnaires were reviewed by the research team based on their relevance to ethical issues in nursing homes. These instruments focused on many different aspects of care, for example, ethical preferences and behaviours, staff competence for proving end of life care, moral distress, hospital ethical climate, moral distress for pharmacy practice, and burnout. Many of the instruments did not focus on ethical issues, but included it as one subscale within the overall instrument. Furthermore, many of the instruments were developed in settings outside the nursing homes. While some of the items from each of the included instruments were useful for identifying the themes to include and the appropriate wording of items, the review of previous instruments further justified the development of a new instrument instead of using an already developed scale. It was recognised that some overlap may be apparent between ethical issues and moral distress, however, the researchers focused on the ethical issues which may have resulted in a range of moral outcomes, one of which may be moral distress.

The items in each survey instrument were grouped thematically. These themes included restraint, confidentiality, autonomy, conflict in relationships, hastening death/prolonging life, lack of resources, the culture and organisation, pain, staff competence, euthanasia, abuse, communication, reporting of errors, human rights, and other miscellaneous issues.

The inclusion of each topic was based on the findings of a qualitative research study conducted prior to the development of the survey instrument (Preshaw et al 2016b). This research study was undertaken to explore RNs' and HCAs' experiences of ethical issues during palliative care provision in nursing homes in one region of the UK (Preshaw et al, 2016b). The core themes raised through 
Ethical issues during palliative care in nursing homes

semi-structured interviews with thirteen RNs and ten HCAs included issues in practice, relational issues, and organisational issues, closely mirroring the findings from the literature. The interview data revealed similar issues between RNs and HCAs including prioritising residents, effective practice, role fidelity, fear of malpractice, issues with residents, families, and staff, lack of resources, organisation of services, quality of services, and staff wellbeing.

The ethical issues identified from these two sets of data were collated into one 31-item survey instrument which was reviewed by the research team. Redundant or repetitive items were removed, leaving 25 items which were taken for preliminary tests via expert panel review and pilot testing. Each item was scored on two Likert Scales where: $0=$ never/none; 1=rarely/little extent; 2=somewhat; 3=frequently/quite an extent; 4=very frequently/great extent. One scale measured the reported frequency of the item and the other scale measured the reported intensity of distress elicited by the item. A mean of 0 on either scale would suggest that the frequency of, or distress from, the ethical issues reported are very low, however, a mean of 4 would mean that there is a high frequency or, or level of distress caused by, the ethical issues across the instrument.

\section{Expert panel review and pilot testing}

Face validity was assessed through an expert panel who reviewed the EPiCNH survey instrument for relevance, readability, and ease of completion. The panel consisted of a clinical and organisational ethicist, a faculty member at the University specialising in palliative and bereavement care, two nursing home dementia services care advisors, and a nursing home manager. The variety of expertise on this panel was able to feed into the ethical nature of the questions, 
Ethical issues during palliative care in nursing homes

the appropriateness of the issues in relation to palliative care, and their suitability for use in a nursing home setting. The feedback was used to edit the layout and question style of the instrument. One additional question was added, adjusting the total number of items to 26 , and the wording of the questions was altered to make it more appropriate for the target population. Additional changes included rewording the style of questions, improving the layout so the Frequency and Distress Scales were more clearly distinguished, and an additional helpline to contact was suggested.

A pilot test was conducted with a convenience sample of four RNs and six HCAs. They completed the 26-item EPiCNH and reported that all the questions were appropriate and understandable, and the layout was straightforward (See appendix two for $\mathrm{EPiCNH}$ ). Responses from the pilot test were not included in the final analysis, however, they allowed the researchers to confirm the face validity of the instrument within the research population.

Stage 2: cross sectional survey

Population and sample: RNs and HCAs in nursing homes were the population of interest. The sample was a convenience sample from privately owned nursing homes across Northern Ireland $(\mathrm{NI})$ who had agreed to participate in the research. The number of staff per home ranged from nine to 100 (Mean=33.2, Standard Deviation $(S D)=24.4)$.

\section{Data collection}

A convenience sample of 23 privately owned nursing homes in $\mathrm{NI}$ were invited to participate in the survey. RNs and HCAs were given the opportunity to complete the EPiCNH survey instrument during their shift, or else complete and 
Ethical issues during palliative care in nursing homes

return it in a sealed envelope within two weeks. Data was collected during October and November 2015 from 18 of the nursing homes. Five nursing homes refused to participate due to: the nursing home being sold; insufficient time available; and no response from manager.

\section{Data analysis}

Data were entered into a MS Excel File and transferred to IBM SPSS Statistics 22 for descriptive and exploratory factor analysis. Frequencies and percentages were calculated for the demographic details of the participants, and mean scores were calculated for each survey item. Principal Axis Factoring and Oblique rotation (direct oblimin) was utilised to explore the responses from 201 participants over the 26 items per Scale. Oblique rotation assumes some correlation between the factors which was anticipated due to the likelihood of the ethical issues functioning dependently on one another. Sufficient sample size was set at greater than five respondents per item, or a minimum of 100 responses (Bryman \& Cramer 1997; Ferguson \& Cox 1993). Factorability was confirmed by calculating a measure of sampling adequacy (KMO) greater than 0.5 (Field 2000), and through a significant Bartlett's test of sphericity. To ensure the data is free from multicollinearity or singularity, a correlation matrix with scores around 0.3 or higher was anticipated (Field, 2000). Multiple methods were utilised to determine the number of factors to extract; the Kaiser Guttman Criteria (Eigenvalues $>1$ ), and a Scree plot. If these methods were in disagreement, both analyses were conducted to check for best fit. Internal consistency was calculated through Cronbach's alpha. While typically 0.7 is cited as the cut off point for an acceptable alpha score (Nunnally 1978), it has 
Ethical issues during palliative care in nursing homes

been suggested that within an exploratory factor analysis, as low as 0.6 is suitable (Suhr \& Shay 2009; Schmitt 1996).

\section{Ethical considerations}

Ethical approval was granted by the School of Nursing and Midwifery Research Ethics Committee (02.DPreshaw.08.15.M7.V4). Participants were supplied with an information sheet and provided informed consent prior to participation. Governance was sought from the manager of each nursing home.

\section{RESULTS}

\section{Participant profile}

In total, 217 surveys were returned, however, 16 were removed as they were left blank. Two hundred and one out of 596 potential participants (33.7\%), from 18 private nursing homes completed the $\mathrm{EPiCNH}$ survey instrument, including 129 HCAs, 69 RNs, and three participants who did not specify their work designation. The mean age was $36.7(S . D=12.55)$ and the majority $(87 \%)$ were female. Most (87.5\%) identified themselves as British or Irish, and the most frequently reported qualifications included a Bachelor of Science in the RN group (44.9\%), and a National Vocational Qualification level three in the HCA group (31.3\%). Over half $(56.2 \%)$ of all participants had worked in the nursing home for less than five years.

\section{Missing data}

In the instance where respondents did not complete an item, the mean scores on the relevant scale for each participant were calculated and utilised in the analysis. No participants left the Frequency scale fully blank whereas 20 participants left the Distress scale fully blank thus was not included in the 
Ethical issues during palliative care in nursing homes

analyses. An analysis was conducted to assess patterns in the sub-group who left the Distress scale blank. Based on this analysis, there is no evidence that a particular group of individuals were likely to miss or avoid the Distress scale.

\section{Psychometric properties of the Frequency Scale}

The final number of participants included in the study was 201 (33.7\% response rate). This sample satisfied the minimum requirements for the analysis as suggested by the literature (Bryan and Cramer, 1997; Ferguson and Cox, 1993). Factorability was confirmed due to the number of correlations greater than 0.3 in the correlation matrix (factor correlations ranged from -.23 to .31), the KMO measure for identity correlation (0.807), and Bartlett's test of sphericity $\left(X^{2}=1454.972\right.$, d.f. $\left.=325, p<.001\right)$. Principal axis factoring with oblique rotation (direct oblimin) was undertaken based on the suggestions of the Kaiser Guttman Criteria (seven factors suggested) and the Scree plot (five factors suggested). A factor analysis with five factors failed to run as it did not fit the dataset, therefore, it was rerun with seven factors. Three weak items (loading less than 0.32 or those that cross-loaded above 0.4 on both) were removed and the analysis was rerun. Four factors were found which were stronger and which could explain $48.7 \%$ of the variance (Table 1 ).

\section{TABLE ONE HERE}

The four factors were named through a research team discussion influenced by the literature and resulted in the following labels; Processes of care (Factor 1); Competency (Factor 2); Resident autonomy (Factor 3); and Burdensome treatment (Factor 4). The reliability of each of the factors was estimated through

Cronbach's alpha (Table 2). Factor one scored highest (.84), followed by factor 
Ethical issues during palliative care in nursing homes

two (.68), factor four (.60), and factor three (.50). Cross loading was evident on three items, however, the removal of these items would not have increased the reliability any further. All factors excluding factor three suggested good internal consistency.

\section{TABLE TWO HERE}

\section{Psychometric properties of the Distress Scale}

Factorability was confirmed due to the number of correlations greater than 0.3 in the correlation matrix (factor correlations ranged from -.47 to .58), the KMO measure for identity correlation (0.89), and Bartlett's test of sphericity $\left(X^{2}=\right.$ 1748.979, d.f. $=325, p<.001)$. Principal axis factoring with oblique rotation (direct oblimin) was undertaken based on the suggestions of the Kaiser Guttman Criteria (five factors suggested) and the Scree plot (five factors suggested). A factor analysis with four factors failed to run as it did not fit the data, therefore, it was rerun with five factors. Five factors explained $63.3 \%$ of the variance and only one item did not substantially load (greater than 0.32), suggesting five factors was a good fit (Table 3).

\section{TABLE THREE HERE}

The five factors were labelled; Processes of care (Factor 1); Resident autonomy (Factor 2); Burdensome treatment (Factor 3); Quality of care (Factor 4); and Communication (Factor 5. The reliability of each of the factors was estimated through Cronbach's alpha (Table 4). Factor one scored highest (.90), followed by factor four (.86), factor two (.78), factor five (.78), and factor three (.39). Seven items cross loaded onto multiple factors, however, the removal of these 
Ethical issues during palliative care in nursing homes

items would not have increased the reliability any further. All factors excluding factor three suggested good internal consistency.

\section{TABLE FOUR HERE}

\section{Descriptive Analyses}

Item level: The items with the highest mean score on the Frequency Scale included item five (I have to care for residents only accepting small amounts or refusing food and fluids near the end of life; Mean= 2.71; $S D=1.19$ ) and item six (I have made a decision in the resident's best interest to prevent them coming to harm or unnecessary risk; Mean=2.68; $S D=1.24)$, both of which fall into the factor of Resident autonomy. The most distressing items were item seven (I witness how poor staff communication results in diminished quality of care to residents; Mean= 2.48; $S D=1.39)$ and item twenty (I don't have enough time to provide the resident with the care she/he needs; Mean=2.36; $S D=1.44$ ) both of which fall into the factor of Processes of care.

Factor level: Table 2 identifies the mean scores on the Frequency Scale per factor which range from .98 (Burdensome treatment) to 2.36 (Resident autonomy). "Resident autonomy" includes items relating to the prevention of harm and risk for both families and residents, for example, lying to residents to prevent them from being hurt and best interests decision making.

There is less variation between the mean scores for each factor in the Distress Scale than the mean scores from the factors in the Frequency Scale, ranging from 1.45 to 1.99 . As displayed in table 4 , the most distressing factor is factor 
Ethical issues during palliative care in nursing homes

one, which presented items relating to the processes of care including lacking resources, the organisation of care, and issues within the staff team.

\section{DISCUSSION}

The 26-item EPiCNH instrument has added to the palliative care knowledge base by considering the ethical issues experienced specifically by RNs and HCAs within the nursing home. The instrument reports on two aspects of an ethical issue experienced in the provision of palliative care, its frequency and the level of distress experienced by the respondent. In the Frequency Scale, items were grouped into four factors; Processes of care; Competency; Resident autonomy; and Burdensome treatment. These factors overlap somewhat with the factors identified in the Distress Scale; Processes of care; Resident autonomy; Burdensome treatment; Quality of care; and Communication. However, further testing is needed prior to implementation in practice. While some items did not load onto any factors, they were retained within the survey instrument and could be investigated further in a future confirmatory analysis.

The qualitative findings which guided the development of the EPiCNH survey instrument (Preshaw et al, 2016), can be seen to link to the factors revealed by the EFA (See appendix 1). While overlap between the qualitative themes and the statistical factors was evident, patterns emerged from the data. The theme of "organisational issues" was strongly linked to "Processes of care," however, some items from the other themes also overlapped into this factor. The theme of "Relational issues" was most often linked to "Resident autonomy," however "Processes of care," were also linked to some of the categories within this theme. The theme of "Issues in practice" consisted of items linked to multiple 
Ethical issues during palliative care in nursing homes

factors, however, this was expected due to the broad range of categories included within this theme.

Processes of care was the largest group for both Scales and encompassed the issues in the overall care journey from decision making, time allocation, communication impacting on care, and lacking the resources to providing the desired care. These areas have been highlighted in the literature, for example, Schaffer (Schaffer 2007) identified these concepts within the theme of "quality of healthcare services," grouping pain relief, financial limitations, communication issues, and limited resources.

Resident autonomy was identified in both Scales and related specifically to minimising the risk of emotional or physical harm while trying to balance an individual's right to choose through not telling the truth, best interests decision making, trying to encourage food and fluids when the resident resists, and reacting when a family member is in distress. Previous studies have similarly identified this paternalistic attitude including Solum et al (2008) and Tabak and Shemesh-Kigli (2006), however, it has also been suggested that paternalism can be prevented against through the use of advanced directives by making the person's requests and preferences for care known to professionals (Linzer et al. 2000).

Burdensome treatment was identified in both Scales and referred to situations in which the participant felt the treatment was unnecessary or beyond what the resident required. This concept can also be seen in the literature, for example, by Gjerberg et al (Gjerberg et al. 2010) in terms of "limitations of life prolonging treatment." This included hospitalisation after pressure from the family, DNR, 
Ethical issues during palliative care in nursing homes

and artificial feeding. These particular items were not approached in terms of the medical necessity of the lifesaving action or hospital treatment, but whether or not the participant found them to be burdensome or unnecessary.

Competency issues were unique to the Frequency Scale and captured the feeling of uncertainty and lack of clarity in terms of training, care instructions and plans, and provision of care. While knowledge was identified as a means of improving overall coordination of care (Dreyer et al. 2011), lack of knowledge, particularly by younger staff members was also acknowledged (Teeri et al. 2006).

Quality of care was a factor unique to the Distress Scale which looked beyond purely the processes of care and towards how they rated the quality of the care provided through the processes of palliative care. Quality of care has also been identified as an ethical issue by healthcare professionals (Enes and DeVries (Enes \& de Vries 2004); Schaffer 2007; Fjelltun et al (2009)). This factor mirrored issues raised through the interviews when participants reported how aspects of the organisation limit the quality of care available.

Communication issues within the healthcare team were identified including lack of written communication and unclear care instructions by senior clinicians. Communication issues within the team were common across the literature (Bolmsjö et al. 2006; Lillemoen \& Pedersen 2013; Enes \& de Vries 2004), however, communication strategies were also used to alleviate ethical issues both within the team and when interacting with residents (Slettebø \& Bunch 2004; van der Dam et al. 2011; Sellevold et al. 2013). 
Ethical issues during palliative care in nursing homes

\section{Study limitations}

The low response rate is a notable limitation of the study. Trends in globalisation and the free movement of Labour within the European Union has led to a high proportion of care staff being from overseas (Lievesley et al. 2011), therefore, with English as a second language they not be comfortable completing a pen and paper survey. The sample for the cross sectional survey was limited to a non-probability purposive sample of RNs and HCAs working in a convenience sample of nursing homes in one region of the UK, therefore, there was no control over the characteristics of people who chose to participate. It is possible that those who chose to participate are systematically different from those who chose not to participate, limiting the scope of generalisability. Furthermore, it is challenging to estimate whether the proportion of RNs and HCAs captured in this study are reflective of the general nursing home staffing, due to a lack of guidelines on staffing levels, nurse to patient ratios, and skill mix within this setting (Royal College of Nursing 2017).

The Distress scale was more frequently left blank compared to the Frequency scale, which may be a problem associated with the design of the survey. Despite many attempts to make the Distress scale clear including an example, a written and verbal explanation of the processes of completing the survey, and the use of different colours and bold lines to differentiate the scales, it is evident that not all participants recognised the Distress scale.

The rigorous process of survey instrument development included a literature review, interviews with key stakeholders to develop items, face validity testing with an expert panel, and pilot testing with the population of interest. Despite this, the factors were formed based on the participant's responses, therefore, it 
Ethical issues during palliative care in nursing homes

is possible that latent variables existed which were not identified due to the characteristics and limitations of the sample.

\section{CONCLUSION}

This study aimed to develop and psychometrically assess the "Ethical issues in Palliative care for Nursing Homes" (EPiCNH) survey instrument. This research has offered preliminary evidence of the psychometric properties of the EPiCNH which identifies the ethical issues experienced by RNs and HCAs providing palliative care in nursing homes within the UK. Factors drawn out through the EFA included processes of care, competency issues in care, conflict of resident autonomy, burdensome treatment, quality of care, and communication issues. Prior to implementation within nursing homes across the UK, further testing including a confirmatory factor analysis would be beneficial to test the strength of the factors. Research could be conducted in other countries with a similar demographic composition and pressure on palliative care resources in nursing homes, to search for similarities and differences based on organisational differences. Future research should further the assessment of reliability and validity for the instrument.

\section{RELEVANCE TO CLINICAL PRACTICE}

This survey instrument could benefit nursing homes by identifying areas of practice that trigger ethical issues for staff facilitating focussed practice improvement initiatives. The two largest factors of processes of care and conflict of resident autonomy highlight the need to address the organisational aspects of caring, and provide training for staff to negotiate conflicting ethical principles. 
Ethical issues during palliative care in nursing homes 
Ethical issues during palliative care in nursing homes

\section{REFERENCES}

Age UK, 2017. Later Life in the United Kingdom, Age UK. Available at: https://www.ageuk.org.uk/Documents/EN-

GB/Factsheets/Later_Life_UK_factsheet.pdf?dtrk=true.

Bolmsjö, I.Å., Sandman, L. \& Andersson, E., 2006. Everyday Ethics in the Care of Elderly People. Nursing ethics, 13(3), pp.249-263.

Bryman, A. \& Cramer, D., 1997. Quantitative Data Analysis with SPSS for Windows: A Guide for Social Scientists, Routledge.

Creswell, J.W. \& Plano Clark, V.L., 2011. Designing and Conducting Mixed Methods Research 2nd ed., Thousand Oaks CA: Sage Publications, Inc.

van der Dam, S.S. et al., 2011. Organizing moral case deliberation experiences in two Dutch nursing homes. Nursing ethics, 18(3), pp.327-40.

Dreyer, A., Førde, R. \& Nortvedt, P., 2011. Ethical decision-making in nursing homes: influence of organizational factors. Nursing ethics, 18(4), pp.51425.

Enes, S.P.D. \& de Vries, K., 2004. A survey of ethical issues experienced by nurses caring for terminally ill elderly people. Nursing Ethics, 11(2), pp.150-164.

Ferguson, E. \& Cox, T., 1993. Exploratory Factor Analysis: A Users' Guide,

Field, A.P., 2000. Discovering Statistics Using SPSS for Windows: Advanced Techniques for the Beginner, Sage Publications.

Fjelltun, A.-M.S. et al., 2009. Carers' and nurses' appraisals of needs of nursing home placement for frail older in Norway. Journal of clinical nursing, 
Ethical issues during palliative care in nursing homes

18(22), pp.3079-88.

Froggatt, K. \& Reitinger, E., 2013. Palliative Care in Long-term Care Settings for Older People: EAPC Taskforce 2010-2012, Available at: https://www.lancaster.ac.uk/media/lancaster-university/contentassets/documents/fhm/dhr/ioelc/FinalReportLongTermCareSettings_Jan22_2013.pdf [Accessed April 25, 2017].

Fromme, E.K. \& Smith, M.S., 2016. Ethical Issues in Palliative Care. UpToDate. Available at: https://www.uptodate.com/contents/ethical-issues-in-palliativecare [Accessed May 26, 2017].

Gjerberg, E. et al., 2010. Ethical challenges in the provision of end-of-life care in Norwegian nursing homes. Social science \& medicine (1982), 71(4), pp.677-84.

Guidelines and Audit Implementation Network, 2013. Guidelines for Palliative and End of Life Care in Nursing Homes and Residential Care Homes, Available at: http://www.hscbereavementnetwork.hscni.net/wpcontent/uploads/2015/05/GAIN-Guidelines-for-Palliative-and-End-of-LifeCare-in-Nursing-Homes-Residential-Care-Homes-Appendix-2-RevisedSeptember-2014.pdf.

Lievesley, N. et al., 2011. The changing role of care homes Bupa with a historical perspective, London: UK.

Lillemoen, L. \& Pedersen, R., 2013. Ethical challenges and how to develop ethics support in primary health care. Nursing ethics, 20(1), pp.96-108.

Linzer, N., Samuel, J. \& Sable, J., 2000. Judaism, professional intervention, and 
Ethical issues during palliative care in nursing homes

ethics in long-term care. Journal of pastoral care, 54(1), pp.33-43.

Nunnally, J.C., 1978. Psychometric theory 2nd ed., New York: NY: McGraw-Hill.

Office for National Statistics, 2014. National Population Projections, 2012-based Reference Volume: Series PP2,

Preshaw, D.H.L., Brazil, K. \& Mclaughlin, D., 2015. Ethical issues experienced by healthcare workers in nursing homes : Literature review. Nursing Ethics.

Royal College of Nursing, 2017. Staffing Levels. Available at: https://www.rcn.org.uk/get-help/rcn-advice/staffing-levels\#Care homes [Accessed January 1, 2017].

Schaffer, M.A., 2007. Ethical Problems in End-of-Life Decisions for Elderly Norwegians. Nursing Ethics, 14(2), pp.242-257.

Schmitt, N., 1996. Uses and abuses of coefficient alpha. Psychological Assessment, 8(4), pp.350-353.

Sellevold, G.S. et al., 2013. Quality care for persons experiencing dementia: the significance of relational ethics. Nursing ethics, 20(3), pp.263-72.

Slettebø, Å. \& Bunch, E.H., 2004. Solving Ethically Difficult Care Situations in Nursing Homes. Nursing Ethics, 11(6), pp.543-552.

Solum, E.M., Slettebø, A. \& Hauge, S., 2008. Prevention of unethical actions in nursing homes. Nursing Ethics, 15(4), pp.536-48.

Suhr, D. \& Shay, M., 2009. Guidelines for Reliability, Confirmatory and Exploratory Factor Analysis. In Western Users of SAS Software: Analytics and Statistics. San Jose. 
Ethical issues during palliative care in nursing homes

Tabak, N. \& Shemesh-Kigli, R., 2006. Sexuality and Alzheimer's disease: can the two go together? Nursing Forum, 41(4), pp.158-66.

Teeri, S., Leino-Kilpi, H. \& Välimäki, M., 2006. Long-Term Nursing Care of Elderly People: identifying ethically problematic experiences among patients, relatives and nurses in Finland. Nursing Ethics, 13(2), pp.116129.

United Nations, 2001. World Population Ageing: 1950-2050, New York: NY. Available

at:

http://www.un.org/esa/population/publications/worldageing19502050/.

United Nations, 2015. World Population Prospects: Key findings and advance tables, New York: NY. Available at: https://esa.un.org/unpd/wpp/Publications/Files/Key_Findings_WPP_2015.p df. 
Ethical issues during palliative care in nursing homes

\section{Appendix 1}

Frequency Key: 1= Processes of care; 2= Competency; 3=Resident autonomy; 4= Burdensome treatment

Distress Key: 1=Processes of care; 2=Resident autonomy; 3= Burdensome treatment; 4=Quality of Care; 5= Communication

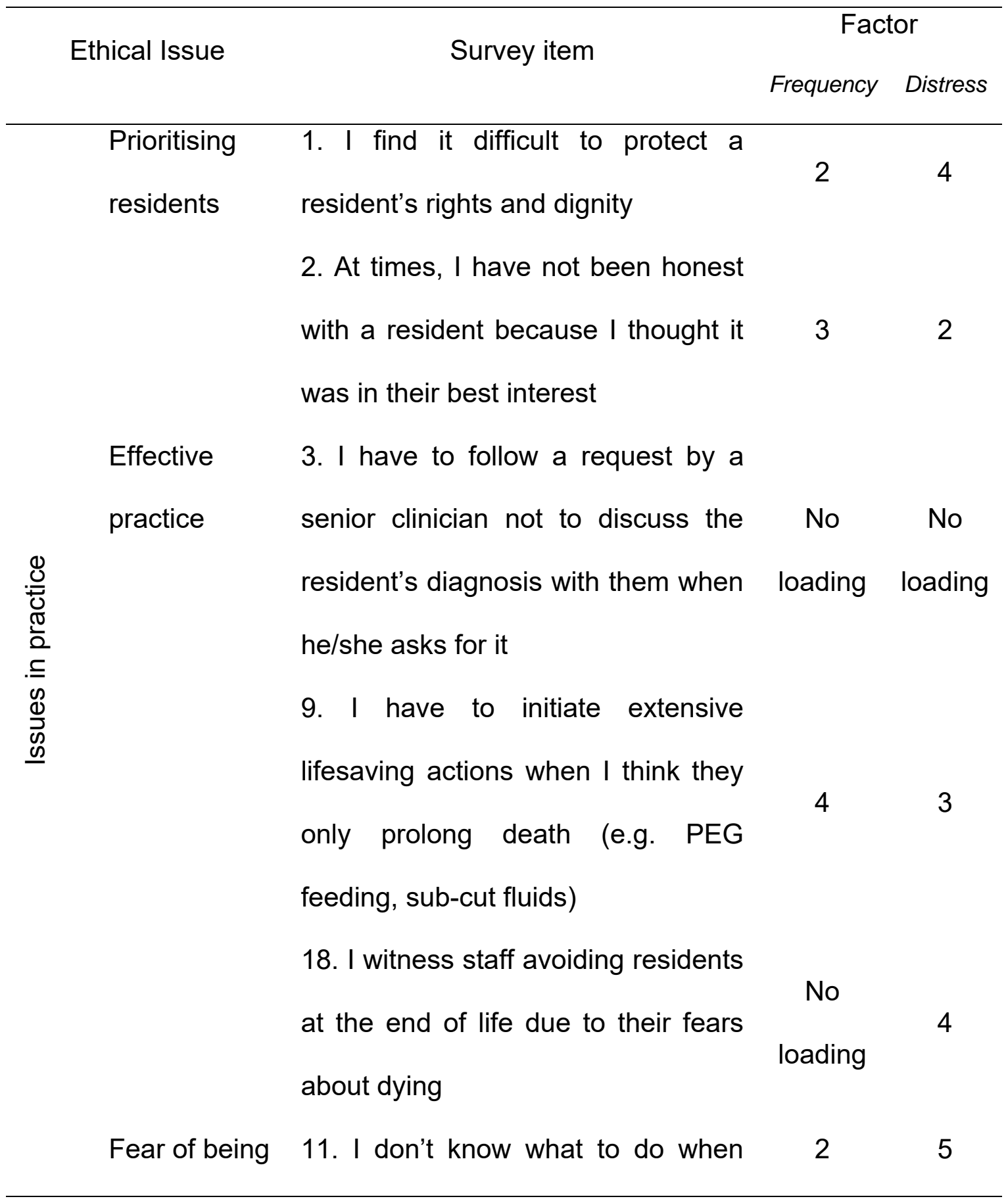


Ethical issues during palliative care in nursing homes

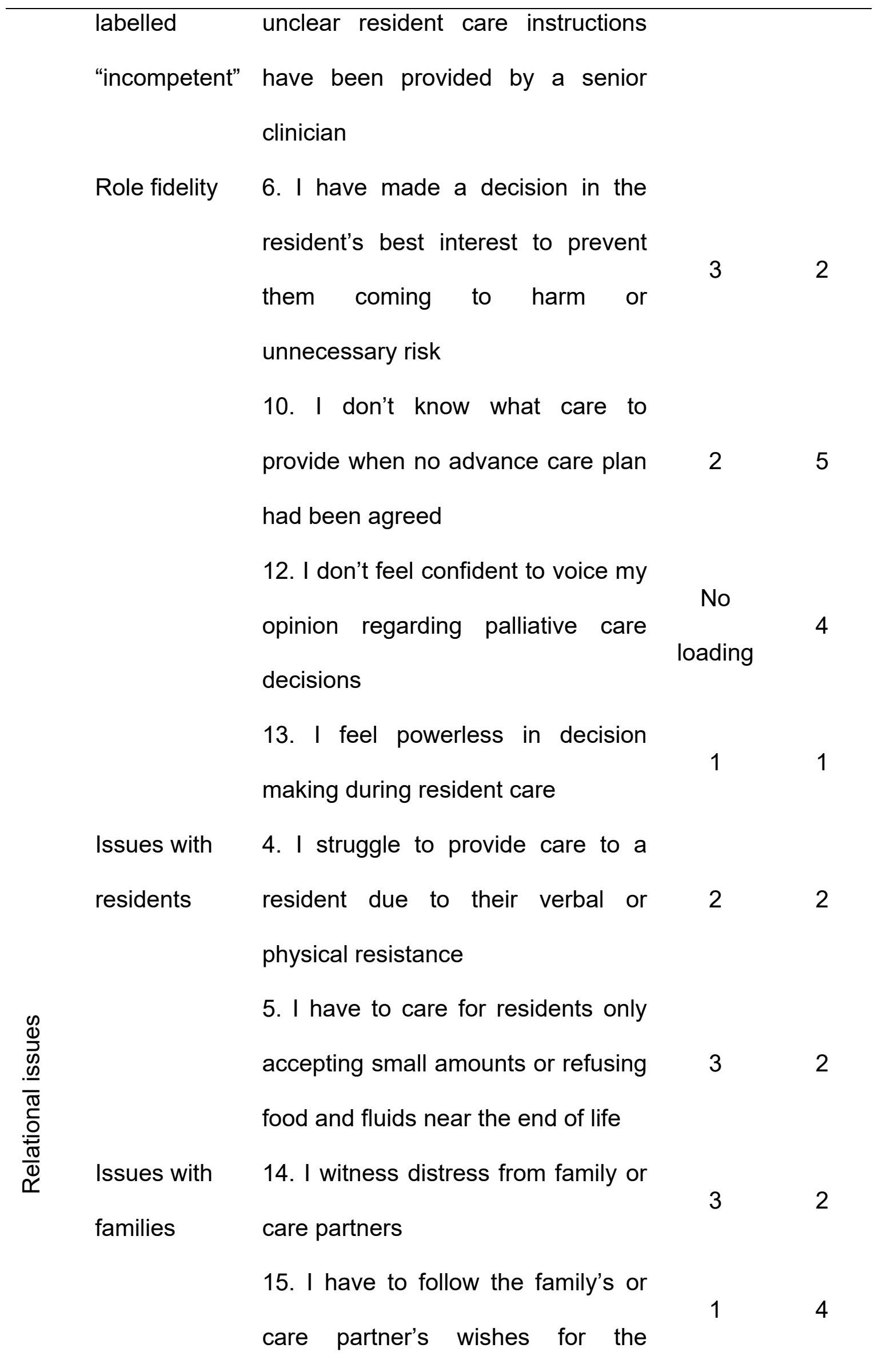


Ethical issues during palliative care in nursing homes

resident's care when I do not agree

with them

Conflicts/ 7. I witness how poor staff

dilemmas communication results in diminished

with quality of care to residents

colleagues

Staff

16. I am asked to provide care to

wellbeing the resident according to a senior

clinician, specialist palliative care

nurse or charge nurse against my

personal or professional opinion

Lack of 19. I am not able to provide the care

resources I want due to lack of resources

within the care home

20. I don't have enough time to provide the resident with the care 1 she/he needs

24. I am involved in non-direct care activities which reduce time spent with the residents

8. I have observed professional incompetence due to insufficient staff training for providing nursing

care 
Ethical issues during palliative care in nursing homes

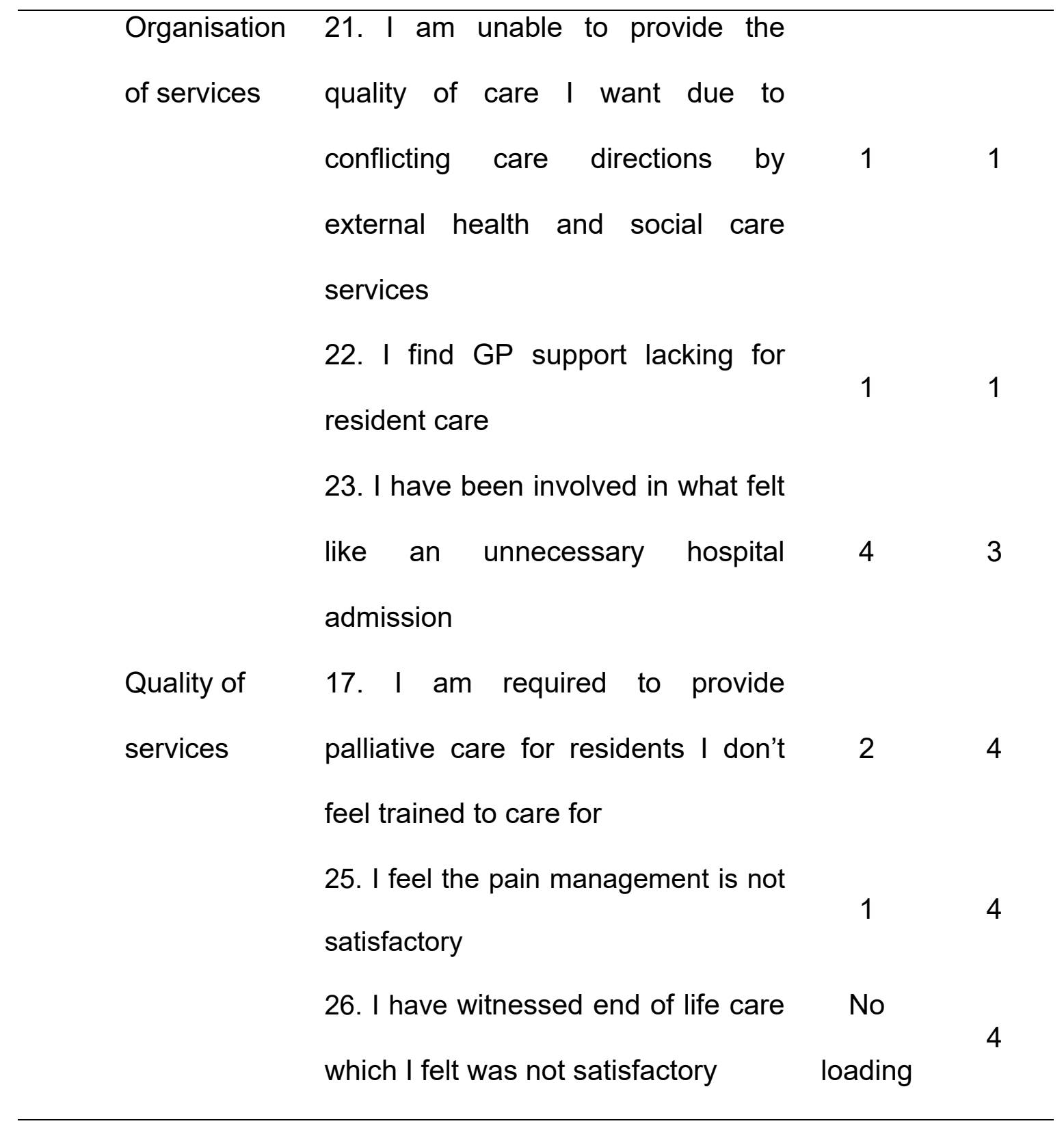


Ethical issues during palliative care in nursing homes

Table 1: Pattern Matrix (Frequency Scale)

Item

Factor

$\begin{array}{llll}1 & 2 & 3 & 4\end{array}$

20 I don't have enough time to provide the

$\begin{array}{llll}.70 & .17 & -.08 & .10\end{array}$

resident with the care she/he needs

25 I feel the pain management is not satisfactory $\quad .68$

$\begin{array}{llll}68 & -.05 & -.12 & -.20\end{array}$

19 I am not able to provide the care I want due to

$\begin{array}{llll}.68 & .15 & .04 & .17\end{array}$

lack of resources within the care home

21 I am unable to provide the quality of care I

.67

$.20 \quad-.15 \quad-.26$

want due to conflicting care directions by external

health and social care services

22 I find GP support lacking for resident care

$\begin{array}{llll}.58 & -.14 & .03 & -.24\end{array}$

13 I feel powerless in decision making during

$\begin{array}{llll}.52 & .21 \quad .00 \quad .09\end{array}$

resident care

24 I am involved in non-direct care activities

$\begin{array}{llll}.51 & .05 & .06 & -.23\end{array}$

which reduce time spent with the residents

15 I have to follow the family's or care partner's

.45

$.07 \quad .06 \quad .01$

wishes for the resident's care when I do not agree

with them

7 I witness how poor staff communication results

$-.08$

.39

.07

in diminished quality of care to residents

8 I have observed professional incompetence due

.37

.21

$.32 \quad-.01$

to insufficient staff training for providing nursing

care 
Ethical issues during palliative care in nursing homes

16 I am asked to provide care to the resident .32

according to a senior clinician, specialist palliative

care nurse or charge nurse against my personal

or professional opinion

11 I don't know what to do when unclear resident

care instructions have been provided by a senior

clinician

17 I am required to provide palliative care for

residents I don't feel trained to care for

10 I don't know what care to provide when no

advance care plan had been agreed

1 I find it difficult to protect a resident's rights and dignity

4 I struggle to provide care to a resident due to

their verbal or physical resistance

2 At times, I have not been honest with a resident

because I thought it was in their best interest

14 I witness distress from family or care partners

$.36-.28$

6 I have made a decision in the resident's best

$-.06 \quad .09$

$.42 \quad .01$

interest to prevent them coming to harm or unnecessary risk $-.07 \quad-.01$ $.41 \quad-.08$ amounts or refusing food and fluids near the end of life 18 I witness staff avoiding residents at the end of 
Ethical issues during palliative care in nursing homes

life due to their fears about dying

9 I have to initiate extensive lifesaving actions

$\begin{array}{llll}-.06 & .21 & .03 & -.65\end{array}$

when I think they only prolong death (e.g. PEG

feeding, sub-cut fluids)

23 I have been involved in what felt like an

$\begin{array}{llll}.20 & -.04 & .08 & -.61\end{array}$

unnecessary hospital admission 
Ethical issues during palliative care in nursing homes

Table 2: Means and Reliability estimates for Factors (Frequency Scale)

\begin{tabular}{llll}
\hline Factor & Mean (SD) & $\begin{array}{l}\text { Number } \\
\text { items }\end{array}$ & $\begin{array}{l}\text { of } \\
\text { alpha }\end{array}$ \\
\hline 1: Processes of care & $1.41(.78)$ & 11 & .84 \\
2: Competency & $1.00(.70)$ & 5 & .68 \\
3: Resident autonomy & $2.36(.73)$ & 4 & .50 \\
4: Burdensome treatment & $.98(.99)$ & 2 & .60 \\
\hline
\end{tabular}


Ethical issues during palliative care in nursing homes

Table 3: Pattern Matrix (Distress Scale)

Item

Factor

\begin{tabular}{lllll}
\hline 1 & 2 & 3 & 4 & 5
\end{tabular}

20 I don't have enough time to provide the

$\begin{array}{llll}-.00 & -.03 & .11 & .04\end{array}$

resident with the care she/he needs

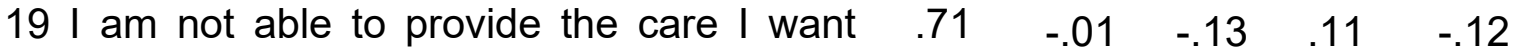
due to lack of resources within the care home

$\begin{array}{lllllll}7 & \text { I witness how poor staff communication } & .57 & .26 & .10 & -.04 & -.05\end{array}$ results in diminished quality of care to residents

24 I am involved in non-direct care activities $\quad .56 \quad \begin{array}{lllll}.06 & .36 & -.02 & -.08\end{array}$ which reduce time spent with the residents

22 I find GP support lacking for resident care $\quad \begin{array}{lllll}.55 & -.02 & .05 & .15 & -.17\end{array}$

8 I have observed professional incompetence $\quad \begin{array}{lllll}.53 & .24 & .24 & -.05 & -.20\end{array}$

due to insufficient staff training for providing

nursing care

$13 \mathrm{I}$ feel powerless in decision making during $\quad .46 \quad \begin{array}{lllll}.07 & -.36 & .36 & -.17\end{array}$ resident care

21 I am unable to provide the quality of care I $\quad \begin{array}{llllll}40 & -.06 & .03 & .28 & -.35\end{array}$ want due to conflicting care directions by external health and social care services 6 I have made a decision in the resident's $\quad-.04 \quad \begin{array}{lllll}.77 & -.13 & -.09 & .03\end{array}$ 
Ethical issues during palliative care in nursing homes

best interest to prevent them coming to harm

or unnecessary risk

$\begin{array}{llllllll}5 & \text { I have to care for residents only accepting } & .01 & .71 & -.02 & .06 & .00\end{array}$ small amounts or refusing food and fluids near the end of life

4 I struggle to provide care to a resident due $\quad \begin{array}{llllll}.02 & .64 & .13 & .07 & -.15\end{array}$ to their verbal or physical resistance

$\begin{array}{lllllll}2 \text { At times, I have not been honest with a } & .06 & .48 & .15 & .05 & .01\end{array}$ resident because I thought it was in their best interest

14 I witness distress from family or care $\quad \begin{array}{llllll}35 & .35 & -.19 & .09 & -.02\end{array}$ partners

23 I have been involved in what felt like an $\quad \begin{array}{llllll}34 & -.12 & .49 & .13 & .02\end{array}$ unnecessary hospital admission

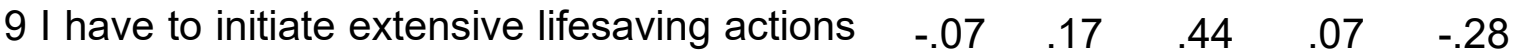
when I think they only prolong death (e.g.

PEG feeding, sub-cut fluids)

12 I don't feel confident to voice my opinion $\quad \begin{array}{lllllll}05 & .10 & -.36 & .67 & -.16\end{array}$ regarding palliative care decisions

17 I am required to provide palliative care for $\quad \begin{array}{llllll}.03 & -.00 & -.03 & .66 & -.10\end{array}$ residents I don't feel trained to care for $\begin{array}{lllllll}26 & \text { I have witnessed end of life care which I } & .12 & -.08 & .36 & .63 & .04\end{array}$ felt was not satisfactory

25 I feel the pain management is not $\begin{array}{llllll}.22 & .12 & .19 & .55 & .19\end{array}$ satisfactory 
Ethical issues during palliative care in nursing homes

18 I witness staff avoiding residents at the $\quad \begin{array}{llllll}-.07 & .04 & .01 & .54 & -.20\end{array}$

end of life due to their fears about dying

16 I am asked to provide care to the resident $\quad \begin{array}{llllll}.28 & .06 & .05 & .49 & .07\end{array}$

according to a senior clinician, specialist

palliative care nurse or charge nurse against

my personal or professional opinion

1 I find it difficult to protect a resident's rights $\quad \begin{array}{llllll}.05 & .25 & .03 & .42 & -.21\end{array}$

and dignity

15 I have to follow the family's or care $\quad .27 \quad \begin{array}{llllll}26 & -.03 & .37 & .09\end{array}$

partner's wishes for the resident's care when I

do not agree with them

$\begin{array}{llllllll}3 & \text { I have to follow a request by a senior } & -.11 & .22 & .20 & .30 & -.29\end{array}$

clinician not to discuss the resident's

diagnosis with them when he/she asks for it

10 I don't know what care to provide when no $\quad \begin{array}{llllll}16 & -.02 & .04 & .01 & -.77\end{array}$

advance care plan had been agreed

11 I don't know what to do when unclear $\begin{array}{llllll}.27 & .19 & -.25 & .17 & -.44\end{array}$

resident care instructions have been provided

by a senior clinician 
Ethical issues during palliative care in nursing homes

Table 4: Reliability estimates for factors (Distress Scale)

\begin{tabular}{llll}
\hline Factor & Mean (SD) & $\begin{array}{l}\text { Number } \\
\text { items }\end{array}$ & of \\
& & $\begin{array}{l}\text { Cronbach's } \\
\text { alpha }\end{array}$ \\
\hline 1: Processes of care & $1.99(1.13)$ & 8 & .90 \\
2: Resident autonomy & $1.98(.90)$ & 5 & .78 \\
3: Burdensome treatment & $1.45(1.09)$ & 2 & .39 \\
4: Quality of care & $1.57(1.04)$ & 8 & .86 \\
5: Communication & $1.55(1.25)$ & 2 & .78
\end{tabular}

